had been thrown off from the lungs; the man at the same time becoming almost exhausted for want of nourishment, which he was not for a time able to take, except in the smallest quantities. After the lapse of a few weeks, the man would rally, eat and drink largely, and go about his work until another paroxysm threatened, when I was again in attendance. On each occa. sion of an attack, I used to say, "Ihis surely will be the last"; so severe and imminent did it appear.

This state of things went on for some time, till at last the thought occurred to me, How is it that asthmatic patients generally live to a good old age? They do not die of consump. tion; nor do the lungs undergo any other change except the dilatation of the air-cells, which dilatation of the cells does not much interfere with their normal action when free from an attack. Thus considering the matter, it appeared to me probable that the original cause of the disease was in the overworked powers of digestion; and I was borne out in this supposition by the circumstance that the patient had respite from attacks as soon as a certain amount of expectoration had been thrown off, and his stomach had for a season rested. Was it not then probable that impurities in the blood were formed by imperfect digestion, which were thrown off by means of the lungs? How far my ideas were correct, the following statement of treatment will, I think, go far to prove.

I speak now of what is called dyspeptic asthma-a disease which I believe to be peculiarly hereditary; that is to say, when the disease has once made its appearance, those who inherit it will ever be liable to attacks from imprudent diet; for I am convinced that an asthmatic person can never with impu. nity eat and drink as other people do. I may here state that, out of the number of cases which $I$ have attended, I found hereditary predisposition in nine out of ten. And if it be true that asthma is an hereditary disease, I will endeavour, by the evidence of cases which I intend to publish, to shew that wherever it has existed in any member of a family for one, two, or even three generations back, exciting causes, such as imprudent diet, an attack of bronchitis, an attack of influenza, derangement of the liver or any other functional derangement, atmospheric influences, peculiar odours, influences of the mind either for joy or sorrow, may at any time or period of life bring to light this peculiar disease, which has hitherto been latent in the system. It is fortunate that stomach-derangement from imprudent diet, etc., is, as far as my experience goes, the most frequent exciting cause-consequently more under the control of medical treatment, provided the patient has resolution enough to second the efforts of the medical attendant in carrying out a strict system of diet and regularity; in fact, it may be said that the scales are thus held with disease and suffering on one side, and comparative health and comfort on the other.

Most of the other patients inherited gout, and in some instances both diseases were traced in the family; and in more than one instance where this was apparent, I found that there were alternate attacks of asthma and gout, which is, I think, an additional evidence that both diseases are hereditary, and may be considered blood-diseases. What the peculiar element in the blood may be which produces either asthma or gout, it is to be hoped scientific researches may one day decide.

To return to my first case. The man in question, possessing some good sense, although he gave himself to beer-drinking and gross eating, as he said, to get up his strength after an attack, after having heard my views of his case, replied, "Well, sir, your remarks appear reasonable enough; and I will endeavour to follow your advice, and not eat and drink so much." I wrote down a system of dietary and general management, which for a season he followed with advantage; after this, he became tired of the plan, and again fell into intemperate habits, with an increase, if possible, of all his original fearful sufferings. He at last became reduced in circumstances, and was obliged to apply for parochial aid. I thought I had now a good opportunity of trying the effects of diet with medical treatment on this patient, and I persuaded him to go into the union house. There I took good care that he should not deviate from my prescribed treatment; for I placed him under lock and key, ordering his food to be regularly given to him, whilst he had a trustworthy attendant when he left his room for the purpose of air or exercise.

His appearance and symptoms at this time were as follows :His countenance bore the signs of great distress. His shoulders were elevated; the eyes protruded; he had no appetite; the stomach was greatly distended after eating; pulse 70 , feeble, yet regular; the tongue was coated, with fissures in it. There was great emaciation, and inability to lie down in bed or to walk up an ascent. The secretions from the bowels were dark. The urine was loaded, shewing an acid deposit.

After giving the patient an alterative pill and a saline aperient, I ordered him the following diet, which was to be regularly weighed out to him, and the hours of meals most strictly attended to. Breakfast at eight o'clock-half a pirit of green tea or coffee, with a little cream, two ounces of dry stale bread; dinner at one o'clock-two ounces of fresh beef or mutton without fat or skin, two ounces of stale dry bread or well boiled rice; three hours after dinner, half a pint of weak brandy and water, or toast-water ad libitum; supper at seven o'clock-two ounces of meat, with two ounces of dry bread. He was not allowed to drink within one hour of his dinner or supper, or till three hours after; at other times, he was not limited. Open air exercise was ordered to be taken as soon as the office of digestion had been performed, but short of fatigue. In addition to this, I ordered him three grains of the extract of conium four times a day, at the hours of seven, twelve, five, and ten; the dose to be gradually increased to five grains four times a day. Under this treatment, in a few days the whole of his distressing symptoms subsided. At the end of a month, he was allowed three ounces of meat twice a day. At the end of two months, he had gained flesh and strength, so that he was able to follow his occupation as a carpenter, which he continued to do without intermission for some years, adhering strictly to the rules laid down for him, which he had now the good sense to adopt.

My views with regard to treatment in the case were simply these: not to give the stomach more to do than it could well accomplish; not to dilute the gastric juices by fluids before or soon after eating, but to allow them to perform alone their proper functions; and to quiet the nerves of the stomach by means of a mild sedative, which prepared it for the due performance of the office of digestion. By this plan, the stomach soon began to crave for food, and a longing for the hour for taking nourishment appeared-good evidence that the powers of digestion were recovering.

Is it not reasonable, then, to suppose that a moderate quan. tity of food, well digested, supplies the system with more pure and nutritious blood than a large quantity of ill dirested food can possibly do? It appears to me not unreasonable that the poison, as it may be called, which is generated by food ill assimilated, finds its way into the circulation; and hence arises the misery of hereditary asthma, which nothing but a paroxysm, and generally a copious expectoration, will relieve. It is my intention in my next paper to give further evidence of the beneficial results of the sedative treatment of dyspeptic asthma.

[To be continuer.]

\section{ON THE EPIDEMIC SMALL-POX IN OXFORD} IN $1854-5$.

By E. L. Hussey, Surgeon to the Radeliffe Infirmary, Oxford, and Stationary Vaccinator of the National Vaccine Establishment.

BeFone the epidemic cholera appeared in Oxford in 1854 several cases of small-pox had occurred; and while the cholera was still raging, and after its ravages were at an end, small-pox spread in the city and neighbourhood more widely than on any former occasion, - at least of late years. (For notice of smallpox in 1844-5, see Mr. W. P. Ormerod, On the Sanatory Condi. tion of Oxford, 1848, p. 33.) Scarlatina, in a severe form, was also extensively prevalent at the same time, and there were many fatal cases. Fever of a low type was also prevalent, and in many cases fatal; measles and hooping.cough were also epidemic.

The late Dr. Ogle (at that time Regius Professor of Physic in the university) wished that some record should be made of the prevalence and severity of the small-pox, and of the circumstances incident to its occurrence; and he purposed to draw up a statistical report of the cases. Not being satisfied with his efforts, he gave over to me the few notes be had collected.

Numeer of CASEs. The resident medical practitioners formed a general estimate, that more than 4000 persons were attacked with the disease in different degrees of severity. The population at that time was probably more than 27,000 , and it was thought that one person in every six was attacked.

The population in August and September $185 \pm$ has been estimated at 26,474 (Memoir on the Cholera at Oxford in 1954, 
by Dr. Acland, p. 29). The " average of seven Novembers", ending 1850, is said to be 27,012 (Report of the Evidence into the State of the Sewerage, etc., of Oxford, 1851, evidence of $\mathrm{Mr}$. Allen, p. 5:3). In December 1850 , the number is estimated at 27,443 (Monthly Report on the Mortality and Public Health of Oxford, annual series iii, by Dr. Greenhill and Mr. Allen).

Of this large number of cases, it was hardly to be expected that accurate notes should have been kept, at a time when such a heavy demand was made upon the services of the medical profession during the prevalence of the other acute diseases then affecting the inhabitants.

At the medical dispensary, 173 cases were entered on the books, upon recommendations of subscribers. But the medical officer (the late Mr. Wood) told me that in many houses where he was visiting he found other members of the family ill, and that he attended them without entering their names on the books of the dispensary. On the whole, he thought he attended 300 cases. 'Two of the number had the disease for the second time; Mr. Wood himself attended them in the former attack.

Mr. Hansard has kept accurate notes of thirty-seven cases among the soldiers of the militia and the recruiting parties stationed here. The greater part of these were admitted into one of the buildings in the yard of the Radcliffe Infirmary, which had been hastily fitted up to receive them. He adds, "There were about thirty other cases in the regiment, but so mild that the febrile symptoms and half a dozen spots were all the indications of the disease. No particular record was taken of them, because they were not sent to hospital."

In the Radcliffe Infirmary, 62 cases came under observation; 27 patients were admitted with the disease upon them-26 from the town, and 1 from Garsington, a village about six miles off -all of these recovered. 31 patients, admitted with other diseases, were attacked; 3 of the nurses caught it, and one of the resident officers. Of the patients in the house, in whom the disease appeared after admission, 3 had not recovered from the small-pox at the time of their death :-

A married woman, aged 34 , with fistulous uicerations about the lower bowel, and other symptoms of unhealthy constitution, was attacked with confluent small-pox, and died after seven days illness.

A butcher, aged 61 , was admitted with mortification of the foot. The leg had rotted of nearly as high as the knee, when he was attacked with confluent small-pox, and died on the 19 th day.

A married woman, aged 40 , with some functional disease of the female system, was attacked with confluent small-pox, and died in about three weeks.

These three patients all exhibited on the arm the cicatrix of former vaccination; it is believed they had not been revaccinated.

One medical practitioner caught the disease, the wife of another, and several children in the family of a third,-all in a mild form.

Diration of the Epidenic. The first case, of which I have any note, was in the parish of St. Ebbe's, in a girl three years old, the child of a stranger resting in the town,admitted a patient of the dispensary on the 17th of July, 1854 .

The last case, also in a patient of the dispensary, was in St. Thomas's parish, in a man aged 25 , admitted a patiert on the 11th of April, 1855.

Number of Deaths. In the Quarterly Returns published by the Registrar.General it is said that, among the deaths in Oxford, 80 cases of sniall-pox had been registered in the last five months of 1854 (Quarterly Return, 1854, No. 24, p. 37), and 25 in the first quarter of 1855 (Quarterly Return, 1855 No. 25, p. 25). But this probably does not include the deaths in the whole district popularly known as forming "Oxford".

For notes of 32 fatal cases, I am indebted to the prac. titioners under whose care they fell. Of these 32 patients, 24 had never been vaccinated; 4 "probably not", at least there is not any reason to believe that they had been; 4 presented marks of vaccination :-

A young gentleman, aged 17, in St. Mary the Virgin's, died under a severe attack of confluent small-pox. He had been vaccinated in childhood, but not revaccinated.

A brewer's man, aged about 50, in Jericho, was revaccinated four days after the operation, he was attacked with confluent small pox, and died in three days.

A girl, aged 21 months, the child of a tramp staying in Jericho, had a single cicatrix on the arm-a doubtful sign at best of the previous vaccine disease.
A baby, aged 2 months, one of a delicate and sickly family in St. Ebbe's. The attack is described as "modified"; an elder sister had it at the same time. In the baby, the vaccine disease had not passed through the regular course, and the only vestige of it was one small mark.

Late one evening, a physician was summoned to a commercial traveller staying at an inn. The general symptoms of small-pox were sufficiently clear, and the characteristic eruption was visible on some parts, though not on the face; his arm presented a good vaccine cicatrix. The patient was in a state of great alarm, saying if it was small-pox, he was sure he should die. The next morning he left the town, travelling by railway. It was afterwards learned that he went to his home in the neighbourhood of London, and died there. No other particulars are known.

The mortality was almost confined to the poor, and amons them chiefly were observed the virulent after-effects of the pestilence.

Generally speaking, the disease was mild in those who exhibited clear marks of former vaccination; there were some few severe cases among such, but not many.

Causes of the EPIDEuIc. It is not necessary to seek far for the exciting cause of a disease so highly contagious. Possibly, it did not arise from a single case only.

A large town is seldom free for any great length of time from cases scattered here and there among the inhabitants and visitors; London is never free. To danger from such a source we are always liable; but among a population protected by vaccination, or by a former attack of small-pox, the imported contagion soon dies out. It only spreads when the mass of the unprotected swells to such an amount that the disease passes readily from one to another, the unsecured population being ready to receive the infection.

A predisposing cause of so severe a visitation may perhaps be found in the habitual neglect of vaccination among the poor, even more than in the imperfect manner in which the vaccination is thought to have been dore. Dr. Ogle often expressed his opinion among his professional friends, that much of the vaccination formerly performed in the town had been done without proper care, and without due supervision of its effects.

However few the facts which are here brought together, yet being of local interest, they are perhaps of sufficient value to be recorded by this Society.* At the late period of the epidemic at which the attempt was made to collect them, it was not found practicable to obtain materials for a complete account of the visitation. Such as they are, they have been put into their present shape in the hope that they will not be thought unworthy of the attention of the members of the Society.

For various notes of cases furnished to Dr. Ogle or to myself, my thanks are due to my colleagues, the physicians and surgeorıs of the infirmary, Dr. Jackson, Dr. Acland, Mr. Hester, Mr. Hansard, and Mr. Symonds, Mr. Briscoe (then house surgeon to the Infirmary), Mr. Coar, Mr. Freeborn, Dr. Giles, Mr. Godfrey, Dr. Leapingwell, Mr. Owen, Mr. Rusher, Mr. Taunton, Mr. Vincent, and Mr. Wood.

\section{Cransactions of 算xancthes.}

\section{BATH AND BRISTOL BRANCH.} THE HYPODERMIC ACTION OF MORPHIA.

By John K. Spender, Esq., Surgeon to the Eastern Dispen. sary, Bath.

[Read April 26th, 1860.]

I BRING the subject of the hypodermic action of morphia before the Society this evening, in order to elicit the experience of those gentlemen who are conversant with that practice. My own experience is very small, and embraces only four cases and these cases illustrate the palliative agency of morphia solely in neuralgic disorder.

I do not know who first devised the hypodermic plan of administering remedies ; but to Dr. Alexander Wood, of Edinburgh, we are indebted for introducing that plan into general

* This paper was read before the Ashmolean Society of Oxford; and though perhaps it may be thought too imperfect for professional literature it is the only record which has been kept of the visitation. 